\title{
A case study in establishing a positive service culture: Attachment and involvement in the workplace
}

Received (in revised form): 9 January 2008

\section{Catherine R. Curtis}

is a doctoral candidate in the Rosen College's Hospitality Leadership doctoral programme at the University of Central Florida. Catherine has over ten years of restaurant management as well as resort accounting experience. Her research interests centre on employee motivation, organisational justice and organisational commitment.

\section{Randall S. Upchurch}

previously was the graduate program director of the Rosen College's graduate degree programmes at the University of Central Florida. Dr Upchurch has over 25 years of industry experience in the lodging industry, and his research interests centre on timeshare resort management, organisational culture, ethics and consumer behaviour.

\section{Abstract}

The purpose of this research is to determine the range of workplace factors that influence employee perceptions of their work environment as what is casually referred to as a 'fun' place to work. The assumption is that a collection of workplace factors (ie, attractors) lead to overall positive benefits for hospitality operators with the foremost being the establishment of a strong service culture. This study begins with a review of emotional contagion, emotional labour, service culture, social bonding theory and from the practitioner 'trade literature' literature, fun in the workplace. In this study, the principal component factor analysis was applied to 572 questionnaires on this compiled scale of reported workplace attractors. The factor analysis procedure indicated that two components were derived that fit well within two aspects of social bonding theory; that of attachment and involvement.

\section{Keywords:}

service culture, positive work environment, attachment, involvement

Journal of Retail and Leisure Property (2008) 7, 131-138.

Catherine R. Curtis

Rosen College of Hospitality Management

University of Central Florida 9907 Universal Blvd Orlando, FL 32819, USA

Tel: +14079038000 Fax: +14079038105 E-mail: catherinecurt@gmail.com doi:10.1057/rlp.2008.5

\section{INTRODUCTION}

A strong service culture is essential to the future success of hospitality organisations because the presence of a service centric culture is associated with elevated employee retention rates, increased morale, heightened productivity and reduced turnover (Berg, 1998; Newstrom, 
2002; Yerkes, 2003). Given the critical role that the hospitality labour force provides to the guest's overall service experience, employers need to gain a better understanding of the systems, practices and procedures than create a service culture that is tailored in such a manner to be personally rewarding to the employee. Therefore, the process of creating a service culture becomes a management process due to the highly personalised nature of the hospitality industry (Lashley, 1999).

Two bodies of research that have focused on understanding this highly personalised and interactive transactional process is that of emotional contagion (Hatfield et al., 1994) and emotional labour (Hochschild, 1983). The basic premise behind emotional contagion is that people 'catch' emotions from others' movements as well as their verbal and nonverbal cues (Hatfield et al., 1993; Doherty et al., 1995). Furthermore, Miller et al. (2007) assert that emotional labour involves the process of managing one's emotions in a manner that is in alignment with organisational goals. Hence, the alignment between an organisation's service culture and that of an individual's emotional display is therefore a managerial process. In essence, research on emotional contagion has focused on identifying and then applying employees' positive emotions in order to better serve the customer (Hennig-Thurau et al., 2006). Furthermore, Perrin (1998) notes that the benefits associated with creating a strong service culture include reduced turnover, reduced stress-related problems, and increased individual and team morale.

Social bonding theory was developed by Hirschi (1969) and proposed four components of positive social behaviour. Two components of social bonding theory seem to encase the concepts within this study, attachment and involvement. These components capture the emotional construct, service construct and the variables that contribute to a positive (fun) work environment and therefore the establishment of a strong service culture.

\section{REVIEW OF RELATED LITERATURE}

Service culture shall be defined as a business that places service as the emphasis of their organisational culture (Teare, 1993). The concept of service culture should not be limited to external customers because true service culture is also practiced for the organisation's internal customers. As service quality is practiced externally, it must also continue internally. Businesses need to acknowledge that their employees are internal customers (Cannon, 2002) that also have needs, wants and problems (Varoglu and Eser, 2006). If these desires are met internally throughout an organisation, the external customer is more likely to be satisfied (Seibert and Lingle, 2007) thus resulting from an internal service chain (Paraskevas, 2001). In order to ensure the development of an internal service chain, the process must be derived through each department within a hospitality organisation as one department serves another (Paraskevas, 2001). Therefore, for a service culture to be achieved, it is essential that organisations strive for successful interdepartmental relationships. Research in interdepartmental relationships has shown more tension than ease of communication. Many factors may be involved including: loyalty to one's department rather than the organisation, more 
knowledge about procedures, goals and rules of one's department, and the difference in priorities may lead to this tension (Paraskevas, 2001).

Frequent communication, however, may aid in the relationships between workflow internal service encounters. Workflow-type service encounters are internal service encounters in which another department is dependent upon another's tasks or accomplishments in the service chain, such as housekeeping and the front desk (Paraskevas, 2001). These departments may receive internal as well as external pressure to perform (Paraskevas, 2001). Managers must be inclined to demonstrate a successful internal service culture to prevent animosity between these departments (Varoglu and Eser, 2006; Seibert and Lingle, 2007). George and Grönroos (1991) suggest four steps in the implementation of a service culture: (1) the organisation must truly support effective service standards, (2) service and human resources must be developed as strategic tactics that are valuable to the organisation, (3) managers and supervisors must believe that these tactics are vital to the success of the organisation and support a service orientation and customer conscious employees, and (4) employees must have an understanding of relationship marketing, employees should know that in addition to their main tasks, they also have a responsibility to do marketing on the firm's behalf. Service culture, however, must be maintained after the implementation so that it does not revert and regress to old habits. Employees must continually be encouraged to remain customer-conscious, employees must receive information and feedback on a regular basis, and marketing campaigns should be launched internally to the employees first, before external customers (George and Grönroos, 1991). As such, the establishment of a strong service culture is beneficial to both the organisation and employee resulting in lesser turnover rates, higher retention, and customer and job satisfaction (Varoglu and Eser, 2006).

Upon an examination of service and emotion literature, two areas of research have focused on the emotions of employees and consumers, emotional contagion (Hatfield et al., 1994) and emotional labour (Hochschild, 1983). According to Hatfield et al. (1994), emotional contagion shall be defined as 'the tendency to automatically mimic and synchronize expressions, vocalizations, postures, and movements with those of another person's, and consequently, to converge emotionally' (p. 5). The theory of emotional contagion attempts to explain how emotions are conveyed in social exchanges and how the process of picking up another person's emotions can affect the social exchange (Hennig-Thurau et al., 2006). There are three elements to emotional contagion: mimicry, feedback and contagion (Hatfield et al., 1993; Doherty et al., 1995). The first element, mimicry suggests that in conversations and interactions people consciously imitate and match their movements with the facial expressions, voices, postures and behaviours of other people. The speed of this process is so rapid that a person trying to mimic someone else's expressions usually looks phoney (Hatfield et al., 1993). Within the second element feedback, subjective emotional experiences that are affected instantaneously derived from the activation/feedback of movements with the facial expressions, voices, postures and behaviours of other people, hence, allowing the emotion to be experienced because 
of the mimicry (Barsade, 2002). Finally, in the last element contagion, people 'catch' the emotions of other people and are aware of the emotions at this point whereas previously it was not conscious (Hatfield et al., 1993, 1994; Doherty et al., 1995).

Emotional labour was defined by Hochschild (1983) as 'labour that requires one to induce or suppress feeling in order to sustain the outward countenance that produces the proper state of mind in others' (p. 7). According to Hennig-Thurau et al. (2006), recent management literature has been examining the use of positive emotional displays to customers. Hochschild (1983) explains the different types of emotional displays utilised in service jobs, surface and deep acting. In surface acting, an employee puts forth emotions that are required for a situation regardless if they are genuinely felt. Real emotions may be suppressed while other emotions are displayed for the benefit of the customer and organisation (Hennig-Thurau et al., 2006). Conversely, deep acting is the expression or display of required emotions by trying to create these emotions themselves. It is the act of displaying a feeling that is selfinduced reminiscent of the method acting technique created by Russian director Constantin Stanislavski (Hochschild, 1983; Hennig-Thurau et al., 2006). The difference in application of surface or deep acting tends to depend on the feeling or emotions of the service provider (Hochschild, 1983).

In reviewing the existing body of emotional contagion, emotional labour, service culture literature there is a paucity of empirical data concerning the need for fun in the workplace. Current research focusing concerning the need for fun in the workplace within hospitality settings is rather sparse as most studies are conceptual in nature. Empirical studies concerning fun work environments is limited to the work conducted by Ford et al. (2003), and later by Karl and Peluchette (2006). To date, very few industry-specific research projects have been conducted on the topic of emotions and service culture with an expressed purpose of improving climate or culture with fun in the workplace. The outcomes of this study enhance what is empirically known about 'fun work environments' based on input collected from a random selection of service managers from the Society of Human Resource Managers. The questionnaire used in this study encompassed ten items that were frequently mentioned in the trade literature as good ways to promote fun in the workplace (Ford et al., 2003). The factors assumed to lead to a fun work environment included: humour (jokes, e-mails, funny messages from management), opportunities for personal development (exercise or craft classes, nonwork related), public celebrations of professional achievements (award banquets, celebrated employees), entertainment (music skits), games (company athletic teams, bingo), fun social events (parties picnics), recognition of personal milestones (birthdays, anniversaries of employment), opportunities to engage in community volunteerism (community service), stress release activities (casual dress day, massages), and friendly competitions among employees (sales contests, attendance award).

A theory that seems to envelop the concepts of emotion, service, and positive work environment is social bonding theory. Social bonding is 
derivative of positive social behaviours that are defined by approach rather than withdrawal or avoidance-type behaviours (Saxena, 2006). Hirschi (1969) developed a social bonding theory while studying juvenile behaviour that highlights four types of social bonds that promote positive social behaviours. These types of bonds are defined as attachment, commitment, involvement and belief. Attachment is defined as having an interest in others. Commitment, the second bond is defined as time and effort to conventional lines of action. Involvement, the third bond, refers to participation in conventional activities. Belief, the last bond deals with conformity to society's values (Hirschi, 1969). The objective of this research is to determine which factors employees perceive to be most important to the contribution of a positive (fun) work environment.

\section{METHODOLOGY}

This study utilises data collected from 572 human resource professionals in a nationwide survey. To collect this information, a six-part survey was designed and delivered by e-mail to 4,000 randomly selected human resource professionals from the Society of Human Resource Management database. The survey was divided into six sections consisting of possible consequences, frequency of practices, utility (contributions) of fun practices, importance of various employee needs, and comprehensive assessment of what embodies a fun work environment, and organisational policies that relate to the creation of a fun work environment.

\section{FINDINGS}

The majority of this workforce sampled was equally male and female (35 per cent), followed by primarily male workforce ( 24.5 per cent), predominantly females (21.2 per cent), dominantly male (12.8 per cent) and dominantly female (6.6 per cent). The education level of the nonexempt workers revealed that 53.7 per cent completed high school, 35.9 per cent had some college and 10.3 per cent were college graduates. The education level of managers displayed that 55.7 per cent were college graduates, 24.4 per cent had some college, 10.3 per cent had some graduate school and 9.6 per cent of managers held graduate degrees. The age profile of nonexempt workers revealed that 50.2 per cent of workers were aged 30-39, 25.7 per cent were aged 40-49, and 24.1 per cent were aged 20-29. Managers' and supervisors' ages yielded a majority (59.2 per cent) in the 40-49 range, followed by the 30-39 age range (29.8 per cent), with some (11 per cent) in the 50-59 age range.

\section{Scale reliability}

A Cronbach's $\alpha$ reliability coefficient was utilised to evaluate the reliability of the utility scale. The resulting coefficient $\alpha$ for factor 1 was 0.720 and 0.686 for factor 2 . The figures are above the minimum value of 0.5 and are close to the acceptable level of 0.7 (Nunnally, 1978).

A factor analysis was conducted on the variables listed in Table 1. These variables were derived from frequently mentioned content within 
Table I: Respondents' perceptions of workplace attractors and involvement

\begin{tabular}{lll}
\hline Variable & Mean & Std. Deviation \\
\hline & & \\
Humour & 3.53 & 0.924 \\
Opportunities for personal development & 3.47 & 0.988 \\
Public celebrations of personal achievements & 4.10 & 0.783 \\
Entertainment & 3.17 & 0.911 \\
Games & 3.44 & 0.899 \\
Fun social events & 4.11 & 0.741 \\
Recognition of personal milestones & 4.20 & 0.775 \\
Opportunities to engage in community volunteerism & 3.59 & 0.913 \\
Stress relief activities & 3.98 & 0.754 \\
Friendly competitions among employees & 3.65 & 0.960 \\
\hline
\end{tabular}

Scale: I = not at all, $2=$ unlabelled between not at all and moderately, 3 = moderately, 4 = unlabelled between moderately and extensively, $5=$ extensively

the fun work environment literature. The focus of the utility scale is the employee's perceptions of each item as a contributor (attractor) to a fun work environment. Before conducting the factor analysis, the KaiserMeyer-Olkin (KMO) test was used to measure sampling adequacy and Bartlett's Test of Sphericity was used to measure the appropriateness of the data for the analysis. The KMO indicated that the variables were interrelated and shared common factors reporting a value of 0.842 . Bartlett's Test of Sphericity was at $\chi^{2}=1452.889, \mathrm{df}=45, p<0.01$ signifying that the data matrix was satisfactorily correlated to the factor analysis.

Exploratory factor analysis with the Varimax rotation was utilised on the data regarding the internal consistency of the ten utility variables. Factor analysis was used to produce correlated variable composites derivative of the original ten variables from the utility scale, and to identify a smaller set of components that would explain most of the variances in the items from the scale. Varimax rotation was used with Kaiser Normalisation identifying three components that explained approximately 60 per cent of the variance. Items were retained if they loaded at 0.4 or more on a factor and did not cross load on any other factor at 0.3 . After an examination of the scree plot it was, however, decided to analyse the data with two components and to remove one variable, 'stress-related activities', that cross loaded into both components. The following factors have been identified:

Factor 1: Attachment. This factor contained four items and explained 25.01 per cent of the variance in the data with an eigenvalue of 3.87. The four variables included were 'Recognition of personal milestones', 'Public celebrations of personal achievements', 'Fun social events' and 'Opportunities to engage in community volunteerism'.

Factor 2: Involvement. This factor contained five items and explained 24.44 per cent of the variance in the data with an eigenvalue of 1.08. The four variables included were 'Entertainment', 'Games', 'Humour', 'Opportunities for personal development' and 'Friendly competitions among employees'. The results of the principal components factor analysis are shown in Table 2. 
Table 2: Results of the factor analysis of utility scale $(n=525)$

\begin{tabular}{|c|c|c|c|c|c|}
\hline Utility variable & $\begin{array}{l}\text { Factor } \\
\text { loading }\end{array}$ & Communality & Eigenvalue & Variance (\%) & Cronbach's $\alpha$ \\
\hline \multicolumn{6}{|l|}{ Factor 1} \\
\hline $\begin{array}{l}\text { Recognition of personal } \\
\text { milestones }\end{array}$ & 0.855 & 0.736 & & & \\
\hline $\begin{array}{l}\text { Public celebrations of } \\
\text { personal achievements }\end{array}$ & 0.820 & 0.690 & & & \\
\hline Fun social events & 0.587 & 0.498 & & & \\
\hline $\begin{array}{l}\text { Opportunities to engage } \\
\text { in community volunteerism }\end{array}$ & 0.494 & 0.330 & 3.87 & 25.01 & 0.720 \\
\hline \multicolumn{6}{|l|}{ Factor 2} \\
\hline Entertainment & 0.759 & 0.608 & & & \\
\hline Games & 0.699 & 0.584 & & & \\
\hline Humour & 0.615 & 0.378 & & & \\
\hline $\begin{array}{l}\text { Opportunities for personal } \\
\text { development }\end{array}$ & 0.521 & 0.324 & & & \\
\hline $\begin{array}{l}\text { Friendly competitions among } \\
\text { employees }\end{array}$ & 0.493 & 0.385 & 1.08 & 24.44 & 0.686 \\
\hline
\end{tabular}

\section{CASE STUDY IMPLICATIONS}

The implications of this combined research indicates that it is in the hospitality operators best interest to create and promote a fun working environment seeing that these emotionally laden factors have proven to be contagious to employees and guests alike, and are associated with the presence of a strong service culture (Ford et al., 2003; Karl and Peluchette, 2006). Therefore, it is in management's best interest to assess, be aware of, and incorporate those elements that attract and involve the worker into the workplace so as to promote a positive service culture. Conversely, the knowledge gained in understanding workplace attractors and involvement indicators can potentially lead to the repairing and rejuvenating an organisation's service culture.

Even though this case study does represent a national sample of service providers it does agree with the previously mentioned hospitality research in that the creation of a strong service culture is associated with elevated employee retention rates, increased morale, heightened productivity and reduced turnover (Berg, 1998; Newstrom, 2002; Yerkes, 2003). Therefore, given the critical role that the hospitality labour force provides to the guest's overall service experience, employers need to gain a better understanding of the systems, practices and procedures that create a service culture that is tailored in such a manner to be personally rewarding to the employee, which in turn leads to heightened productivity and improved organisational metrics (Berg, 1998; Newstrom, 2002; Yerkes, 2003; Varoglu and Eser, 2006).

In closing, the primary message from this present case study therefore is for hospitality operators to assess and construct the types of systems, practices, and procedures that attract and engage the worker into the existing service culture given the obvious benefits to the worker, the organisation and to their customer base. 


\section{LIMITATIONS}

There are several limitations in this study. The findings cannot be generalised to the Society of Human Resource Management because of the low response rate (14.3 per cent). Possible research efforts may include retest with a more representative sample. As this was research in progress, it has only begun to explore the implications of the utility scale. Further research may include more empirical study on social bonds and positive work environment, and the use of demographic variables as possible predictors for utility items.

\section{References}

Barsade, S.G. (2002). The ripple effect: Emotional contagion and its influence on group behavior. Administrative Science Quarterly. 47, 644-675.

Berg, D. (1998). Humor@work: The power of play. The Journal for Quality and Participation. 21(5), 54-55.

Cannon, D.F. (2002). Expanding paradigms in providing internal service. Managing Service Quality. 12(2), 87-99.

Doherty, R.W., Orimoto, L., Singelis, T.M., Hatfield, E. \& Hebb, J. (1995). Emotional contagion: Gender and occupational differences. Psychology of Women Quarterly. 19, 355-371.

Ford, R.C., McLaughlin, F.S. \& Newstrom, J.W. (2003). Questions and answers about fun at work. H.R. Human Resource Planning. 26(4), 18-33.

George, W.R. \& Grönroos, C. (1991). Developing customer-conscious employees at every level: Internal marketingin Congram, C. and Friedman, M. (eds.), The AMA Handbook of Services Marketing, AMACOM, New York, pp. 85-100.

Hatfield, E., Cacioppo, J.T. \& Rapson, R.L. (1993). Emotional contagion. Current Directions in Psychological Science. 2(3), 96-99.

Hatfield, E., Cacioppo, J.T. \& Rapson, R.L. (1994). Emotional Contagion, Cambridge University Press, Cambridge, England.

Hennig-Thurau, T., Groth, M., Paul, M. \& Gremler, D.D. (2006). Are all smiles created equal? How emotional contagion and emotional labor affect service relationships. Journal of Marketing. 70, 58-73.

Hirschi, T. (1969). Causes of Delinquency, University of California Press, Los Angeles.

Hochschild, A. (1983). The Managed Heart: Commercialization of Human Feeling, University of California Press, Berkeley.

Karl, K. \& Peluchette, J. (2006). How does workplace fun impact employee perceptions of customer service quality? Journal of Leadership and Organizational Studies. 13(2), 2-13.

Lashley, C. (1999). Employee empowerment in services: A framework for analysis. Personnel Review. 28(3), 169-191.

Miller, K.I., Considine, J. \& Garner, J. (2007). "Let me tell you about my job" Exploring the terrain of emotion in the workplace. Management Communication Quarterly. 20(3), 231-260.

Newstrom, J.W. (2002). Making work fun: An important role for managers. S.A.M. Advanced Management Journal. 67(1), 4-8.

Nunnally, J.C. (1978). Psychometric Theory, McGraw-Hill, New York.

Paraskevas, A. (2001). Internal service counters in hotels: An empirical study. International Journal of Contemporary Hospitality Management. 13(6), 285-292.

Perrin, S. (1998). A serious business. Accountancy, (February): 40-42.

Saxena, G. (2006). Beyond mistrust and competition-the role of social and personal bonding processes in sustaining livelihoods of rural tourism businesses: A case of the Peak District National Park. International Journal of Tourism Research. 8, 263-277.

Seibert, J. \& Lingle, J. (2007). Internal customer service: Has it improved. Quality Progress. 40(3), 35-40.

Teare, R. (1993). Designing a contemporary hotel service culture. International Journal of Service Industry Management. 4(2), 63-73.

Varoglu, D. \& Eser, Z. (2006). How service employees can be treated as internal customers in the hospitality industry. The Business Review. 5(2), 30-35.

Yerkes, L. (2003). How to create a place where people love to work. The Journal for Quality and Participation. 26(4), 47-50. 